\title{
SAFETY ENGINEERING FOR THE RELATIVISTIC HEAVY ION COLLIDER AT THE BROOKHAVEN NATIONAL LABORATORY*
}

\author{
Stephen V. Musolino, Steven F. Kane and Joseph W. Levesque \\ Brookhaven National Laboratory, P.O. Box 5000, Upton, New York 11973-5000 \\ *Work performed under the auspices of the U. S. Department of Energy \\ under Contract No. DE-AC02-98CH10886
}

\begin{abstract}
The Relativistic Heavy Ion Collider (RHIC) is a high energy particle accelerator built to study basic nuclear physics. It consists of two counter-rotating beams of fully stripped gold ions that are accelerated in two rings to an energy of $100 \mathrm{GeV} /$ nucleon. The rings consist of a circular lattice of superconducting magnets, $3.8 \mathrm{~km}$ in circumference. The beams can be stored for a period of five to ten hours and brought into collision for experiments during that time. The first major physics objective when the facility goes into operation is to recreate a state of matter, the quark-gluon plasma, that has been predicted to have existed at a short time after the creation of the universe. There are only a few other high energy particle accelerators like RHIC in the world. Each one is unique in design and contains systems and hazards that are not commonly found in general industry. Therefore, the designers of the machine do not always have consensus design standards and regulatory guidance available to establish the engineering parameters for safety. Some of the areas where standards are not available relate to the cryogenic system, containment of large volumes of flammable gas in fragile vessels in the experimental apparatus and mitigation of a Design Basis Accident with a stored particle beam. The ASME Code requires Charpy testing of welds at cryogenic temperature, but testing at $4 \mathrm{~K}$ is nearly impossible to conduct. Engineered welds were used to provide an equivalent level of safety. A cryogenic system is a process system. The RHIC system was designed first by selecting a safe operating mode, then analyzing to ensure this mode was preserved. Cryogenic systems have unique processes, and the safe mode will surprise most process engineers. The experimentalists require detectors to be designed to meet the need of the physics objectives, but the application of standard construction techniques would make research mission impossible. Unique but equivalent safety engineering must be determined. The rules promulgated in the Code of Federal Regulations under the Atomic Energy Act do not cover prompt radiation from accelerators, nor are there any State regulations that govern the design and operation of a large superconducting collider. Special design criteria for prompt
\end{abstract}

radiation were developed to provide guidance for the design of radiation shielding.

\section{INTRODUCTION}

The scope of the RHIC Project was to design, construct, and bring into operation a colliding beam facility, which will enable studies of nuclear phenomena in relativistic energy heavy ion collisions. The collider, which consists of two concentric rings of superconducting magnets, was constructed in a tunnel of $\sim 3.8 \mathrm{~km}$ circumference located in the northwest section of the Brookhaven National Laboratory (BNL) site. Figure 1 depicts the layout of the facility. The collider is to be able to accelerate and store counterrotating beams of ions, ranging from hydrogen (protons) to gold, up to kinetic energies of $100 \mathrm{GeV} / \mathrm{u}$ ( $\mathrm{GeV}$ per nucleon) for gold ions and $250 \mathrm{GeV}$ for protons. The store duration for gold in the energy range of 30 to $100 \mathrm{GeV} / \mathrm{u}$ is expected to be approximately $10 \mathrm{~h}$. The layout of the tunnel and the magnet lattice enables the two rings to intersect at six locations along their circumference where the counter-rotating beams collide.

For the scientific mission of the complex four of the six intersection regions have been developed with experimental particle detectors for the "Day-1" facility. The other two regions are for future development, if and when the physics needs justify expansion. Four experiments have been constructed in the intersection regions, two "large" and two "small" detectors systems. One of the large detectors, PHENIX, will be discussed in this paper.

Normal beam loss in a superconducting collider, such as, RHIC. must be small for the collider to efficiently operate. However, some potential for worst-case faults exists which may dominate the passive shielding requirement in a given location. In practice, the radiological controls and posting employed to mitigate the hazards caused by beam loss will be consistent with regulatory requirements (USDOE 1993). However, at most locations surrounding a superconducting accelerator, the maximum possible radiation field corresponds to the improbable occurrence of losing an entire beam at 


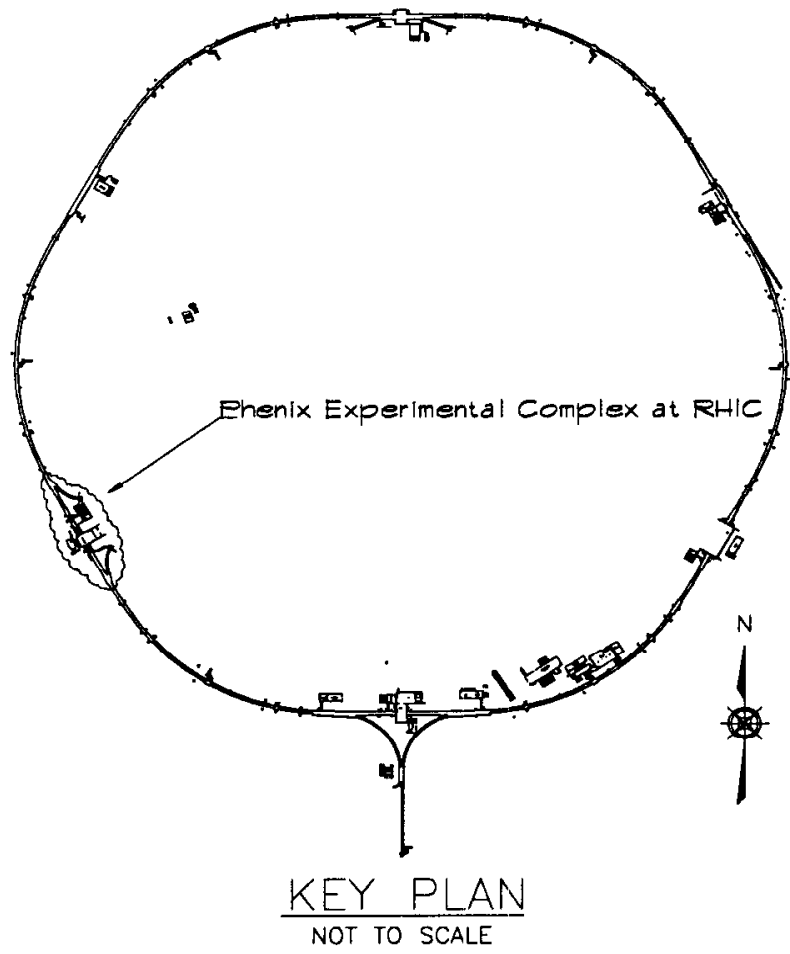

full energy due to a fault. Unfortunately, standards, such as those used for protection of the general public, were not intended to apply to this type of (short duration) radiation field or scenario. They are more appropriately applied when the dose equivalent is delivered over long time frames with high probabilities of occurrence, i.e., the regulations do not set limits on the definition of an uncontrolled area for accelerator "accidents". Because the existing regulatory and guidance documents do not explicitly address fault scenarios for RHIC beam loss, a scheme to provide guidance for shielding design and a means to classify a hierarchy, was developed (Stevens et al 1994).

\section{DESIGN CRITERIA FOR PROMPT RADIATION Beam Loss in the RHIC Facility}

Systematic beam losses in a superconducting accelerator are limited by the ability of the magnets to sustain their superconducting state in the presence of particle losses. Particles leaving the beam pipe of the accelerator deposit energy in the form of a cascade of hadronic and electromagnetic particles. These interactions typically give rise to a significant temperature rise, which is, at a maximum, several meters from the initial interaction point. A temperature rise of more than $0.5^{\circ} \mathrm{K}$ is sufficient to destroy the superconducting state of the $\mathrm{Nb}$-Ti wire (a quench). Several hours are then required to cool the magnets back down to the $4^{\circ} \mathrm{K}$ operating temperature. During this time, the accelerator is non-operational. The amount of energy needed to initiate a magnet quench is $\sim 4 \mathrm{~mJ} / \mathrm{g}$ of superconductor and can be achieved by a loss of as little as 1 part in $10^{4}$ of the circulating beam. Since such a small amount of beam loss can cause significant disruption to the operating program, superconducting accelerators are effectively loss free during normal operations. Small amounts of particle losses are intercepted by collimators, beam scrapers and a rapid acting $(<\mathrm{ms})$ beam removal system that is used to protect the magnets from the onset of beam loss by directing the beam onto a well shielded external beam dump.
It should be noted that when beam loss occurs, there is typically $3.97 \mathrm{~m}$ of sand shielding over the Collider and Transfer Line. An additional $1.8 \mathrm{~m}$ of sand is over the Collider in the vicinity of the Collider Center, which is occupied by non-radiation workers, $0.6 \mathrm{~m}$ over the Collimators and 1.5 m over the Collider Beam Dump.

\section{Design-Basis Accident Fault}

A worst-case fault in the collider would be the loss of the full beam at full energy at an arbitrary point (any magnet or device which intrudes into the physical aperture). Although it was concluded that the maximum credible fault would be full beam loss at points which are near the limiting aperture of the collider and loss of one half of the full beam at other locations, and that such occurrences should be allowed for at a rate of once in several years, for the purpose of evaluating necessary shielding and access restrictions as applied to a specific location, the design-basis accident (DBA) will be assumed to be the maximum credible fault once per year.

\section{Controlled and Uncontrolled Area Classifications}

Existing DOE regulatory requirements do not explicitly consider low probability fault situations for accelerators (USDOE 1993; USDOE 1998). The RHIC criteria uses the International Commission on Radiological Protection (ICRP) concept of dose averaging (ICRP 1990) and adopts the philosophy that both low occupancy and low probability of faults mitigate allowable dose in a single year if a multi-year average dose for a given individual is acceptably low. Four area classifications are defined where personnel are allowed without restriction by physical barriers. These areas are categorized according to whether or not personnel allowed access have been trained as radiation workers (areas posted as controlled) and according to whether the occupancy is expected to be "high" (i.e., continuous as defined by $2000 \mathrm{~h}$ per year) or "low", defined as a region with an occupancy factor (OF) of $1 / 16(1 / 2 \mathrm{~h}$ per $8 \mathrm{~h}$ day) or below (NCRP 1976). Regions with intermediate occupancy will be treated as if they are high occupancy areas.

\section{Design Criteria}

I. Classification "A": Radiation workers; high occupancy Normal loss $0.002 \mathrm{mSv} \mathrm{h}^{-1}$, DBA Fault $5 \mathrm{mSv} \mathrm{y}^{-1}$ limit

II. Classification "B": Radiation workers; low occupancy Normal loss $0.032 \mathrm{mSv} \mathrm{h}^{-1}$, DBA Fault $10 \mathrm{mSv} \mathrm{y}^{-1}$ limit

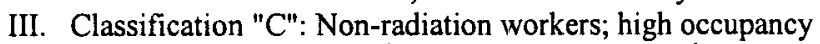
Normal loss $0.15 \mathrm{mSv} \mathrm{y}^{-1}$, DBA Fault $0.1 \mathrm{mSv} \mathrm{y}^{-1}$ limit

IV. Classification "D": Non-radiation workers; low occupancy Normal loss $2.4 \mathrm{mSv} \mathrm{y}^{-1}$,DBA Fault $1.6 \mathrm{mSv} \mathrm{y}^{-1}$ limit

Normal loss is typically from beam-gas, intra-beam scattering, limiting aperture collimators, and small losses that successfully trigger the collider beam abort.

Four of the eight criteria are for regions accessible without restriction by physical barriers. The classifications are distinguished by occupancy and by whether radiation worker training is required for entry. Each classification is specified by limits on dose equivalent resulting from both anticipated beam loss and from design basis accident faults. Although no explicit regulatory requirements exist for low probability faults, the highest proposed fault limits, $10 \mathrm{mSv} \mathrm{y}^{-1}$ in low occupancy regions restricted to radiation workers and $1.6 \mathrm{mSv}^{-1}$ in low occupancy uncontrolled regions, are compatible with several recommendations (Shleien 
1992) that consider infrequent exposures and multi-year dose averaging for given individuals.

In anticipation of a future regulatory change to the mandated Neutron Quality Factor to convert absorbed dose-to-dose equivalent, the weighted Quality Factors were doubled for the purpose of design. Operational controls for prompt radiation; e.g., posting, will be based on existing regulations (USDOE 1998).

\section{WELDING CRYOGENIC COMPONENTS}

In the Relativistic Heavy Ion Collider (RHIC) over 1700 superconducting magnets are enclosed within a cryogenic pressure vessel to provide cooling to a temperature less than $4.6 \mathrm{~K}$. The U.S. Department of Energy and the American Society of Mechanical Engineers (ASME) Boiler \& Pressure Vessel Code requirements, coupled with the cryogenic system design and manufacturing cost parameters, require a weld yield strength of $900 \mathrm{MPa}$ for the $4.8 \mathrm{~mm}$ thick stainless-steel magnet shells, a Ferrite Number (FN) less than 3 for weld processes other than gas tungsten arc welding (GTAW) and gas metal arc welding (GMAW), and a lateral expansion greater than $0.38 \mathrm{~mm}$ for a Charpy V-Notch (CVN) impact test at the operating temperature. Recent studies show that a specimen cannot be transferred from a $4 \mathrm{~K}$ cooling bath to the test machine quick enough to avoid exceeding the test temperature by a large margin. Furthermore, the adiabatic heating associated with deformation often increases the specimen temperature by $70 \mathrm{~K}$ or more, making the test invalid. Engineered welds were used to meet the intent of these requirements.

Fracture mechanics calculations conducted for several cases showed that the fracture toughness $\left(\mathrm{K}_{\mathrm{Ic}}\right)$ of the magnet should be at least $68 \mathrm{MPa} \sqrt{\mathrm{m}}$ at $4 \mathrm{~K}$. Current data indicate a one-sigma scatter band of $+/-44 \mathrm{MPa} \sqrt{\mathrm{m}}$. This indicates the nominal fracture toughness value must be at least $156 \mathrm{MPa} \sqrt{m}$ to guarantee a $95 \%$ confidence level is achieved. This requirement places the necessary fracture toughness at the upper boundary for commercially available weld metal.

Weld toughness is affected by many factors. The presence of delta ferrite and nonmetallic inclusions are well known detractors of toughness. Typical compositions (types 308 and 316) used for cryogenic stainless welds generally fall about $40 \%$ below base metals in their $\sigma_{\mathrm{y}}$ versus $\mathrm{K}_{\mathrm{Ic}}$ performance. Welds with a FN greater than 7 show relatively low toughness, but welds with a lower FN are scattered within the one-sigma scatter band.

An inverse relationship exists between yield strength and fracture toughness. Other research establishes that a Charpy absorbed energy of at least 32 Joules is necessary to meet the ASME minimum lateral expansion of 0.015 in. $(0.38 \mathrm{~mm})$. The following equation uses $76 \mathrm{~K} \mathrm{CVN}$ impact energy as a function of $\mathrm{FN}$, calculated from the Schaeffler Diagram (ferrite potential if negative), carbon content, and nickel content (Siewert et al 1997):

$$
C V N(J)=19-1.4 F N-890 C^{2}+1.4 N i
$$

This equation indicates a CVN of $32 \mathrm{~J}$ is not possible with $\mathrm{FN}$ greater than 2, carbon content greater than $0.03 \mathrm{wt} . \%$, and nickel content less than 12 wt. $\%$.

Weld strength at $0.20 \mathrm{wt} \% \mathrm{~N}$ increases by a factor of 2 as temperature is decreased from $298 \mathrm{~K}$ to $76 \mathrm{~K}$, and increases by a factor of 2.5 when the temperature is decreased to $4 \mathrm{~K}$ for the same $0.05 \%$ nitrogen. Studies also show that increasing the nitrogen from the typical weld nitrogen content of $0.05 \%$ to a nitrogen content of $0.20 \%$ yields a threefold increase in strength when cooled to $4 \mathrm{~K}$. The solubility limit for nitrogen is a function of the composition, with certain elements, such as manganese, serving to increase the limit. Nickel also has a significant, though nonlinear, effect on toughness. Increasing nickel from $10 \%$ to $20 \%$ provides the greatest improvement in toughness. Thus, a weld with at least $20 \%$ nickel should exhibit the greatest attainable toughness for an austenitic stainless steel.

Fully austenitic compositions may be subject to solidification cracking. Studies show this tendency can be controlled by limiting the "tramp" elements, phosphorus and sulfur, that produce a lowmelting-point eutectic. Sometimes fully austenitic grades can be made less sensitive to solidification cracking by adding elements such as manganese, copper, or carbon that change the solidification structure.

By combining the desirable ranges for the various elements, and working with electrode manufacturers, we adopted the composition specification detailed in Table 1 .

Table 1. New Alloy Electrode Specification

\begin{aligned} \hline Element & \multicolumn{1}{c}{ Range (\%) } \\ \hline Carbon & $0.02 \max \\$ Manganese & $7.0-7.2 \\$ Silicon & $0.2-0.5 \\$ Phosphorous & $0.018 \max$ (desired as low as possible) \\ Sulfur & $0.004 \max$ (desired as low as possible) \\ Chromium & $20.9-21.7 \\$ Nickel & $24.75-25.25 \\$ Molybdenum & $4.75-5.25 \\$ Copper & $1.25-1.75 \\$ Nitrogen & $0.17-0.21 \\$ Oxygen & 0.015 max (desired as low as possible) \\ Other & $<0.50 \\$ Iron & Remainder \end{aligned}

In the weld, oxygen combines with other elements to form oxide inclusions. Inclusions are harder than the surrounding metal matrix, serving as impediments to the plastic flow of atoms during deformation. Reducing the density and size of inclusions increases the toughness of a weld. Studies have shown that toughness correlation with inclusion spacing is similar for wrought material (Kane et al 1997).

Welds will have a higher inclusion content because of the imperfect shielding of the metal while molten. Welding processes, such as laser, electron beam and GTAW, can produce welds with lower inclusion contents and produce welds with toughness at the upper side of the scatter band. GMAW is preferred for higher production rates, but the process might not produce adequate mechanical properties unless tightly controlled. BNL selected a modern weld power source employing a proprietary, constantcurrent power supply with a patented, pulse-width-modulated, constant-voltage control. This feature provides the ability to optimize the pulsed-spray arc and process characteristics using a set of direct unit controls, yielding a cleaner weld with more consistent composition and microstructure.

Mechanical testing for this alloy found the $0.2 \%$ offset yield strength ranged from $868 \mathrm{MPa}$ to $995 \mathrm{MPa}$, and the ultimate tensile strength ranged from $1222 \mathrm{MPa}$ to $1412 \mathrm{MPa}$. A minimum value of 
$26 \%$ has been obtained for total elongation and $24 \%$ for reduction of area. The fracture toughness results ranged from $218 \mathrm{MPa} \sqrt{\mathrm{m}}$ to 286 $\mathrm{MPa} \sqrt{\mathrm{m}}$. The weld metal's fracture properties decreased with increasing inclusion volume fraction, and that the inclusion volume fraction was proportional to the weld metal oxygen content up to about $0.08 \%$. Charpy V-Notch testing was conducted at three temperatures. CVN energies at $76 \mathrm{~K}$ ranged from $136 \mathrm{~J}$ to $174 \mathrm{~J}$, and room temperature energies from $193 \mathrm{~J}$ to $243 \mathrm{~J}$. CVN energies increased an average of $25 \mathrm{~J}$ with a $25 \%$ reduction in oxygen content, or a $36 \%$ reduction in inclusion density. Lateral expansion increased with oxygen content and inclusion density, contradicting the decrease in impact energy, but consistently decreased with temperature. Lateral expansion ranged from $1.15 \mathrm{~mm}$ to $1.64 \mathrm{~mm}$ at $76 \mathrm{~K}$, and at room temperature from $1.45 \mathrm{~mm}$ to $2.39 \mathrm{~mm}$. Lateral expansion decreased an average of $26 \%$ with a $25 \%$ reduction in oxygen content, or with a $36 \%$ reduction in inclusion density. The data also show increased scatter with increased oxygen content, and a sharper decline in lateral expansion at lower temperatures with increased oxygen content.

Weldability is a significant concern, especially in a production environment, and shielding gas has a major role. Adequate GMAW weldability was achieved with the addition of $1 \% \mathrm{CO}_{2}$ to the shielding gas, and this addition did not adversely affect cryogenic material properties. Hot cracking has not been experienced with this superaustenitic weld alloy. Preliminary testing showed marked improvement in GTAW weldability with hydrogen added to the shielding gas with no effect on mechanical properties.

\section{Design For Safety}

The RHIC magnets are cooled by the world's largest helium refrigerator. The gas inventory is over eight million cubic feet of gaseous helium when warm. With an expansion ratio nearly 700:1, this process system required significant attention for both personnel safety inside RHIC enclosures and inventory preservation. Release of a large volume of helium does not pose a hazard to either the onsite or off-site public as it aggressively diffuses in air. Design of the cryogenic distribution system began with definition of the safe mode for foreseeable failures. The plant would be operating for a majority of the year, and, once cold, it is desirable to keep the gas cold to minimize operating costs. Thus, the plant will be in the "cold" mode nearly all of the facility's operational life. Additionally, a total power outage was a reasonably foreseeable event, having occurred at least twice in the past decade. It was concluded that the safe mode for cryogenic distribution system was the "cold" mode. This is contrary to most process system design philosophies, so a review of the ramifications is in order.

The magnets and all cold process lines are housed in insulated vacuum jackets to reduce the heat load to the refrigerator, similar to a dewar. In actuality, during a power outage, the magnets would act as a large dewar, taking over 24 hours to reach the maximum working pressure with the design heat load.

RHIC also needed warm gas storage. The proposed design used an existing high pressure storage facility. Investigation found the compressors for the 1,000 psi storage facility could not meet the $300 \mathrm{~g} / \mathrm{s}$ maximum flow rate for the warming gas. Our intended design became a storage facility with the same maximum allowable working pressure as the rest of the plant. For power outages, this design uses the rising gas pressure due to warming to move gas into the storage area. A cryogenic liquid storage facility also was developed. The advertised benefit was energy conservation for small or isolated warming of magnets, but it had significant benefit for the power-out scenario. Pressurized gas from the warming magnets during the power outage would flow through J-T valves into the cryogenic liquid storage dewars. This could continue for several days before liquid quality deteriorated to the point that this was no longer beneficial. This extended the power outage duration for the RHIC magnets to more than three days before inventory would be jeopardized.

Other design features for the cryogenic distribution system include relief devices for all potentially closed volumes. This includes the closed volumes created by valve operations.

\section{PHENIX FIRE PROTECTION DESIGN}

The PHENIX Detector consists of three magnets (1 Central and 2 Muon) and four instrumented spectrometers or arms located in a $1055 \mathrm{~m}^{2}$ hall. The East and West CENTRAL ARMS (inner detectors, tracking system, Ring Imaging Cerenkov (RICH) detector, time-of-flight system, and electromagnetic calorimeters) are instrumented to detect electrons, photons, and charged hadrons. The North and South MUON ARMS are instrumented with tracking chambers and particle identifiers to detect muons. To carry out the physics mission of the detector, flammable gas is used in the particle detector systems (see Table 2). The integrated detector has an inventory of over $150 \mathrm{~m}^{3}$ with $80 \mathrm{~m}^{3}$ of pure ethane gas in the $\mathrm{RICH}$.

The RICH counter also has an entrance window area of 8.3 square meters and an exit window of 21.6 square meters. The gas pressure relief settings are:

Overpressure during normal operation: $\quad 0.5^{\prime \prime}$ water column

Maximum tested overpressure:

Burst disk pressure will be set at:

Resealable pressure relief valve set at:

Pressure interlock shuts off inlet gas at:

$1.5^{\prime \prime}$ water column

$1.5^{\prime \prime}$ water column

$1.0^{\prime \prime}$ water column

Underpressure expected during

emergency purge:

$0.75^{\prime \prime}$ water column

-0.1 " water column estimate. FEMA calculations for the exit window support beams (the worst case) predict that they would support up to $25^{\prime \prime}$ water column, at a deflection of $5 "$. Whether the Kapton would fail before that is unkown. In three destructive tests, $8^{\prime} \times 4^{\prime}$ prototype windows failed at overpressures in excess of 50" water column.

A study was performed to analyze the potential for damage due to explosion and fire (BNL 1999). The Design Basis Accident (DBA) for the detector assumes the release of the full inventory of all gas systems (unlikely due to the separation of gas systems and their low pressures) and forms a homogenous cloud prior to ignition. The events postulated do show that the damage does not involve areas outside of the normally unoccupied area, but would destroy a major portion of the equipment valued at $\$ 60 \mathrm{M}$. Because traditional engineering controls to protect against fire and explosion hazards would interfere eliminate the ability to conduct the experimental mission of the detector, equivalent means employed to provide equivalent safety. This protective arrangement within the $\mathrm{PEH}$ is considered equivalent to the Class I Division II electrical equipment rating required for occasional exposure to combustible gases. The specially fabricated electronics cannot be rated for Class I Division II environment due to the experimental physics requirements and impractical nature of fabricating explosion proof detector electronics. Time and cost of the testing by nationally recognized testing laboratory is prohibitive. 
Table 2. Flammable Gases Used in PHENIX

\begin{tabular}{llc}
\hline & Gases Used & $\begin{array}{l}\text { Total } \\
\text { Detector } \\
\text { Volume (m3) }\end{array}$ \\
\hline Detector & $\mathrm{Ar} / \mathrm{C}_{2} \mathrm{H}_{6}(50 \% / 50 \%)$ & 5.6 \\
Drift Chamber (DC) & $\mathrm{Ar} / \mathrm{C}_{2} \mathrm{H}_{6}(50 \% / 50 \%)$ & 1.12 \\
$\begin{array}{l}\text { Pad Chambers (PC) } \\
\text { Time Expansion }\end{array}$ & $\mathrm{Ar} / \mathrm{CH}_{4}(90 \% / 10 \%)$ & 11.5 \\
$\begin{array}{l}\text { Chamber (TEC) } \\
\text { Ring Imaging }\end{array}$ & $\mathrm{C}_{2} \mathrm{H}_{6}(100 \%)$ & 80 \\
$\begin{array}{l}\text { Cherenkov Counter } \\
\text { (RICH) }\end{array}$ & \\
$\begin{array}{l}\text { Muon Tracker (Mu Tr) } \\
\text { Muon Identifier }\end{array}$ & $\mathrm{CF}_{4} / \mathrm{C}_{4} \mathrm{H}_{10}(50 \% / 50 \%)$ & 2.92 \\
(Mu ID) & $\mathrm{CO}_{2} / \mathrm{C}_{4} \mathrm{H}_{10}(91 \% / 9 \%)$ & 59 \\
\hline
\end{tabular}

Release and ignition of gas in the Intersection Region (IR) have been addressed by:

1) flow limits in supply lines and limitations on on-line quantities for flammable gas systems,

2) solid metal piping from the supply to the detector distribution systems (with the exception being at the base of both carriages and the Muon Magnet System where a flexible pipe is used),

3) requirements for leak checking of piping systems upon installation and after modification,

4) detector chambers are designed to ensure window integrity (burst safety factor)

5) pressure tests that assure chamber construction meets design boundary limits including repetitive cycles of over and under pressure,

6) designs that "fail-safe" with loss of power (i.e., fail safe to purge flammables with inert gases),

7) combustible gas detection in the regions where gas could be released and could collect,

8) highly sensitive smoke detection (HSSD) within the detector and at the IR ceiling to promptly indicate off normal conditions,

9) interlocks to shut off all power to the Detector in the event of fire alarm conditions from within the Detector (Detector purge/vent is also started),

10) fusing of power distribution system on printed circuit boards within the PHENIX Detector to limit max front end power dissipation potential (limited to 80 watts maximum),

11) mechanical protection for chamber windows that may expand during over pressurization and contact electronics,

12) continuous pressurization of electronic racks and $\mathrm{AC}$ power distribution panels with fresh air to prevent flammable gas contacting non-rated electrical equipment (loss of pressurization drops power to rack),

13) normal ventilation with fresh air exchange in the IR to dissipate combustible gases,

14) $100 \%$ fresh air purge, activated with interlocks, in the IR to dilute and remove released gases (one air change every six minutes within the hall),

15) monitoring of oxygen content in the PPM range of flammable detector gas in the detector system,

16) for all "conventional" equipment brought into the interior of the IR, Class I, Division II criteria was imposed for classification of electrical devices. Guidance was used from the National Fire Protection Association to establish boundaries between the detectors in which ignition sources were addressed.

\section{REFERENCES}

Brookhaven National Laboratory, Relativistic Heavy Ion Collider, May 1999, "Safety Assessment Document."

International Commission on Radiological Protection, 1991, "1990 Recommendations of the International Commission on Radiological Protection," Oxford: Pergamon Press; ICRP Publication 60; Ann. ICRP 21 (1-3).

Kane, S. F., Siewert, T. A., McCowan,C. N. and Farland, A. L., 1997, "Welding Consumable Development for a Cryogenic (4 K) Application," Advances in Cryngenic Engineering (Materials), 44A:97.

National Council on Radiation Protection and Measurements, 1976, "Structural Shielding Design and Evaluation of Medical Use of X-Rays and Gamma Rays of Energies Up to $10 \mathrm{MeV}$," Washington, D.C., NCRP, Report No. 49.

Stevens, A., Musolino, S., Harrison, M., 1994, "Design Criteria for Prompt Radiation Limits on the Relativistic Heavy Ion Collider Site," Health Physics 66:300-304.

Shleien, B., 1992, "The Health Physics and Radiological Health Handbook," First Printing, Silver Spring, Scinta Inc.

Siewert. T. A., and McCowan, C. N., 1992, "Joining of Austenitic Stainless Steels for Cryogenic Applications," Advances in Cryogenic Engineering (Materials), 38B:109.

United States Department of Energy, 1993, 10 CFR 835 Occupational Radiation Protection, Federal Register, Washington, D.C.

United States Department of Energy, November 1998, "Safety of Accelerator Facilities," Washington, D.C., USDOE, Report No. DOE 0420.2 . 